\title{
WIND MODELING FOR LARGE CONTAINER VESSELS: A CRITICAL REVIEW OF THE CALCULATION PROCEDURE
}

\author{
THIBAUT VAN ZWIJNSVOORDE ${ }^{1}$, LUCA DONATINI ${ }^{1}$, WIM VAN HOYDONCK ${ }^{2} \&$ EVERT LATAIRE \\ ${ }^{1}$ Ghent University, Belgium \\ ${ }^{2}$ Flanders Hydraulics Research Antwerp
}

\begin{abstract}
With the increasing size of container ships, accurate methods to model manoeuvring and mooring conditions are indispensable. Especially in confined waters, where the ship speed is low or even zero, wind forces add a significant contribution to the force balance. The calculation of wind forces is typically done using wind coefficients based on wind tunnel tests. In these computations, a reference wind pressure must be used which is often based on the wind speed at $10 \mathrm{~m}$ height. When the wind blows over a rough surface however, the wind profiles become non-uniform, resulting in much higher wind speeds near the top of the ship, for the same wind speed at $10 \mathrm{~m}$ height. In case of differences between the wind profile used in the wind tunnel and the one expected in the reality, an appropriate reference pressure should be used. A method proposed by Blendermann to calculate such reference pressure is applied in this paper to a wind force calculation for an ultra large container ship. It is shown that, depending on the roughness of the surface, the reference pressure can be a factor 2 to 3 higher than the one corresponding to $10 \mathrm{~m}$ height. This means that wind forces are potentially highly underestimated. The results of the method are compared with CFD simulations with a uniform and non-uniform inlet profile. The comparison shows a good agreement between Blendermann's method and computational fluid dynamics (CFD) results for the surge force and roll moment. On the other hand, Blendermann's method seems to overestimate the sway force, but more simulations are needed before a firm conclusion can be drawn. Keywords: wind coefficients, ULCS, wind profile, reference pressure, CFD
\end{abstract}

\section{INTRODUCTION}

Ports worldwide are facing big challenges to offer safe conditions for manoeuvring, berthing and mooring as ship sizes keep increasing. For container vessels, there is a trend to move to ultra large container ships (ULCS), which account for $18 \%$ of the total container capacity nowadays [1]. These larger ships visit the existing port infrastructure, which has often been designed for a smaller design ship. For container ships, it is not only the length and beam which increase: with each added container tier, the air draught rises as well. The increase of all three dimensions leads to larger wind surfaces and thus larger wind forces acting on the ship.

The forces are often calculated by taking into account aerodynamic wind coefficients, mostly determined based on wind tunnel tests. Available sources for these coefficients are scarce, and they often only consider a limited number of loading configurations. For container ships, these are typically the fully stacked and ballast conditions while uneven stacking conditions are not usually considered. On top of this, the change in wind speed over the height of the ship can be significant, especially for ships with large air draughts, like large container vessels. Over a rough surface, e.g. a container yard with gantry cranes and container stacks, the wind speed varies significantly with altitude, with low wind speeds at the ground level and significant wind speeds at the level of the bridge. This change of wind speed should be taken into account in the choice of reference wind pressure to be used for wind force calculations. This paper focusses on this aspect and suggests a way to deal with it. 
The paper starts with a presentation of the wind force model, including a discussion on vertical wind profiles and the use of wind coefficients. The following section deals with the calculation of wind pressure over the height of the ship for wind profiles associated with rough terrains. A method published by Blendermann [2] is discussed. The method provides a way to compute a reference wind pressure, taking into account the difference between the wind profile used in the wind tunnel and the actual wind profile encountered in the real case scenario. The calculated reference wind pressure should be used in the wind force equations to obtain accurate results. This approach is compared with the common simplified assumption of just considering the wind pressure corresponding to the wind speed at $10 \mathrm{~m}$ height, often called 'reference wind speed' [3]. In the last section, the results of CFD computations in a uniform and non-uniform wind field are presented and compared with the Blendermann's method.

\section{WIND FORCE MODEL}

The effect of a turbulent wind field on the ship's hull and superstructure is complex, as the flow in reality varies in time $(t)$ and space $(x, y, z)$. In the current paper, the velocity only depends on the height $(z)$ above the surface. There is no variation in time $(t)$ and in the horizontal plane $(x, y)$. The conventions used in the current discussion are shown in Fig. 1. For the discussion in this paper, a moored container ship (with a large windage area) is used. The UASC Barzan, presented in Significant ships 2015 [4], is taken as reference. The main characteristics of this ship are given in Table 1. The ship height or air draught is defined as the vertical distance between the highest point on the ship (bridge) and the waterline. In this
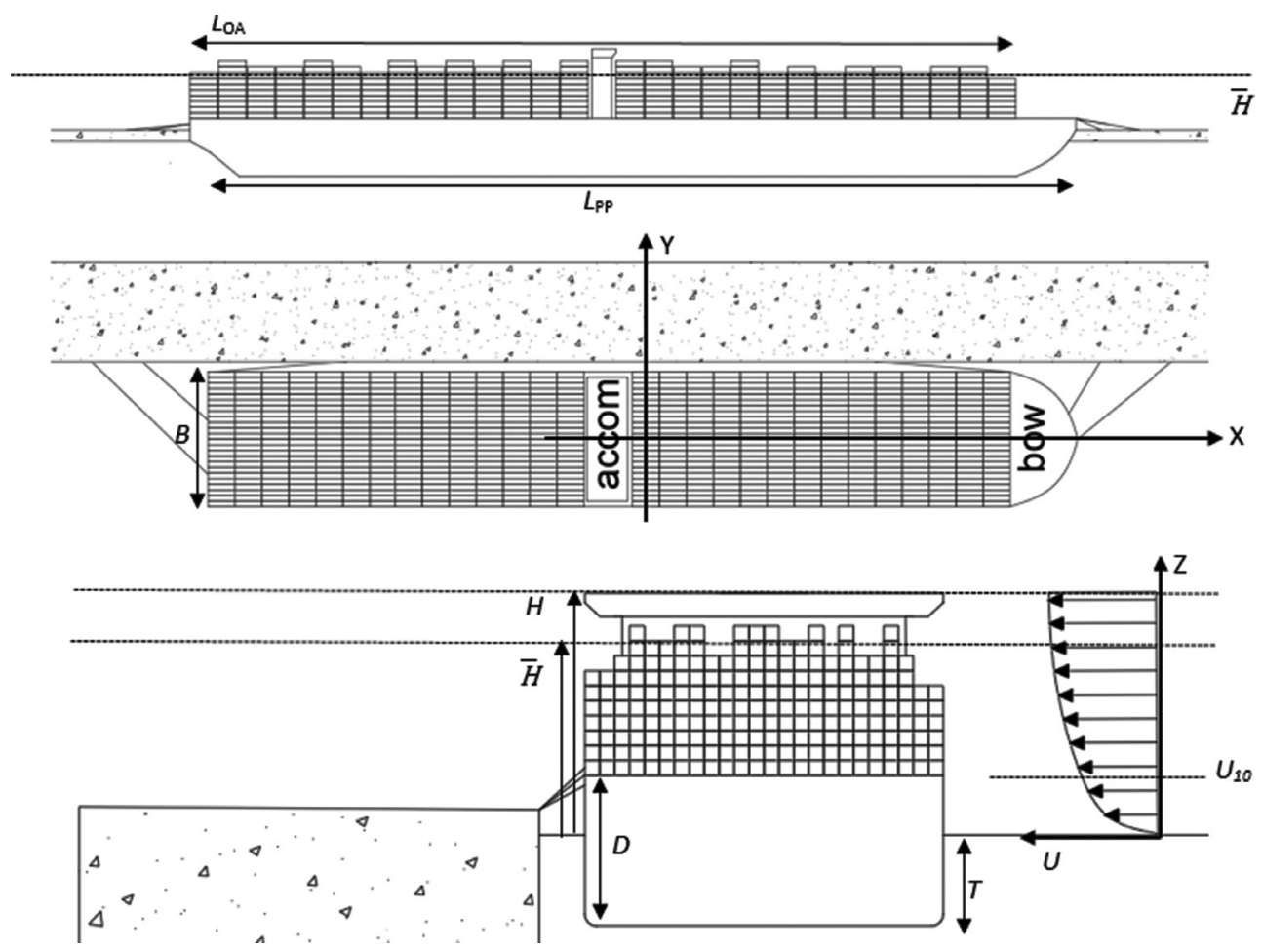

Figure 1: Definitions and conventions. 
Table 1: Main dimensions of UASC Barzan [4]

\begin{tabular}{lccc}
\hline Variable [unit] & Value & Variable [unit] & Value \\
\hline$L_{\mathrm{OA}}[\mathrm{m}]$ & 400.0 & $D[\mathrm{~m}]$ & 30.6 \\
$L_{\mathrm{pp}}[\mathrm{m}]$ & 383.0 & $T[\mathrm{~m}]$ & 14.5 \\
$B[\mathrm{~m}]$ & 58.6 & $A_{\mathrm{f}}\left[\mathrm{m}^{2}\right]$ & 3,146 \\
$H[\mathrm{~m}]$ & 56.1 & $A_{1}\left[\mathrm{~m}^{2}\right]$ & 17,583 \\
$\bar{H}[\mathrm{~m}]$ & 44.0 & & \\
\hline
\end{tabular}

paper, the mean height $\bar{H}$ (eqn (1)) is used, which is the ratio of the lateral wind surface to the length overall. This definition has been used by Blendermann and is used in his method to calculate the reference wind pressure.

$$
\bar{H}=\frac{A_{l}}{L_{\mathrm{OA}}}
$$

2.1 Wind force calculation

Wind forces are generally calculated as is shown in eqn (2a-2d)

$$
\begin{aligned}
& X=C_{\mathrm{X}}(\varphi) \cdot q_{\mathrm{ref}} \cdot A_{1} \\
& Y=C_{\mathrm{Y}}(\varphi) \cdot q_{\mathrm{ref}} \cdot A_{1} \\
& N=C_{\mathrm{N}}(\varphi) \cdot q_{\mathrm{ref}} \cdot A_{1} \cdot L_{\mathrm{PP}} \\
& K=C_{\mathrm{N}}(\varphi) \cdot \mathrm{q}_{\mathrm{ref}} \cdot A_{1} \cdot H \\
& q_{\mathrm{ref}}=\frac{1}{2} \cdot \rho_{a} \cdot U_{\mathrm{ref}^{2}}
\end{aligned}
$$

The wind forces $(X, Y, N, K)$ are a function of a reference dynamic pressure $\left(q_{\mathrm{ref}}\right)$, lateral wind area $\left(A_{1}\right)$, the length between perpendiculars $\left(L_{\mathrm{PP}}\right)$ and the ship height $(H)$. The reference pressure $q_{\text {ref }}$ is calculated based on the reference velocity $U_{\text {ref }}$ and the air density, $\rho_{\mathrm{a}}$. The aerodynamic effect of the wind on the ship is captured in the wind coefficients $C_{\mathrm{X}}, C_{\mathrm{Y}}, C_{\mathrm{N}}$ and $\mathrm{C}_{\mathrm{K}}$. The value of these coefficients is a function of the incoming wind direction $(\varphi)$. In this paper, the choice of $U_{\text {ref }}$ is the main point of discussion. The relationship between wind speed and wind force is quadratic, which highlights the importance of this parameter.

\subsection{Wind profile}

The shape of the wind profile is a function of the terrain roughness. In turn, terrain roughness depends on (and increases with) the distribution and size of obstacles on the surface. The wind speed is lowered due to friction with the ground, and it reaches the geostrophic wind speed at the top of the atmospheric boundary layer $(\delta)$. For the present discussion, it is assumed that the ship is completely immersed in this layer. 


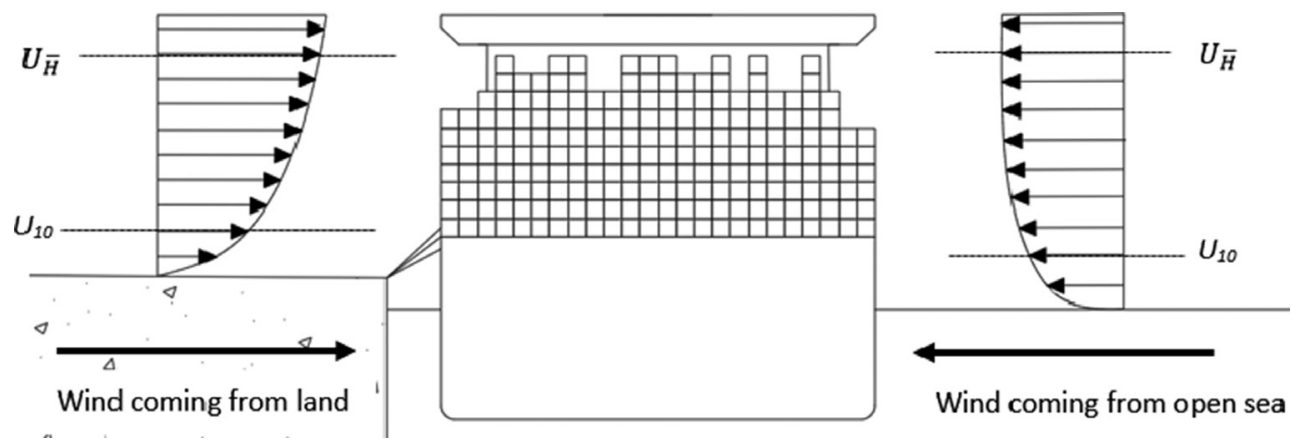

Figure 2: Sketch showing wind coming from land (high roughness) and coming from open sea (low roughness).

The lack of obstacles means that roughness is lower for wind blowing from sea as compared to wind blowing from land. The difference between these two profiles is sketched in Fig. 2. Despite this difference, for most practical engineering applications, no distinction is made between wind profiles.

Wind profiles are usually defined based on the wind measured at $10 \mathrm{~m}$ above the surface $\left(\mathrm{U}_{10}\right)$, which is generally considered to be the reference wind speed $\left(\mathrm{U}_{\text {ref }}\right)$.

The wind profile can be described using mathematical expressions. The two most common profiles are the power law (e.g. [5]) and the logarithmic law (e.g. [6]). In this paper, only the logarithmic profile is discussed. Its general form is given by

$$
U(z)=\frac{u_{*}}{\kappa} \cdot \ln \frac{z}{z_{0}}
$$

where $z$ is the height above water line/earth, $\kappa$ is the Von-Karman coefficient $(\sim 0.4), u_{*}$ is the friction/shear velocity and $z_{0}$ is the roughness length.

Figure 3 shows several logarithmic profiles and a comparison with a uniform wind profile. The terrain roughness for the four conditions is listed in Table 2. The roughness lengths for grass and town are taken from [8] which discusses wind effects on structures, as most research in this field has been done for (high-rise) buildings. For wind coming from open sea, the roughness is lower, as there is less friction. The profile will thus be closer to the uniform profile, as can be seen in Fig. 3. The shape depends mostly on the sea state, with higher waves leading to an increase in roughness. This has been discussed by several authors. Charnock [9] proposed the expression in eqn (5), which links the surface roughness with the shear velocity of the wind. In this equation, $g$ is the gravitational acceleration and $\alpha$ is the Charnock coefficient. For this paper, a value of $\alpha=0.0144$, as proposed by Garatt [7], is used.

$$
z_{0}=\alpha \cdot \frac{u_{*}^{2}}{g}
$$

Figure 3 clearly shows that for a measured wind speed of $10 \mathrm{~m} / \mathrm{s}$ at $10 \mathrm{~m}$ height, the type of terrain has a significant influence on the shape of the wind profile. The question now is what speed should be taken as the reference wind speed, for a given set of wind coefficients. This 
Table 2: Terrain roughness $z_{0}[\mathrm{~m}][7,8]$.

\begin{tabular}{llll}
\hline Uniform & Open sea & Grass & Town \\
\hline $0^{*}$ & 0.0002 & 0.1 & 1.0 \\
\hline
\end{tabular}

*For a uniform profile, the wind speed is constant, indicated here with zero roughness.

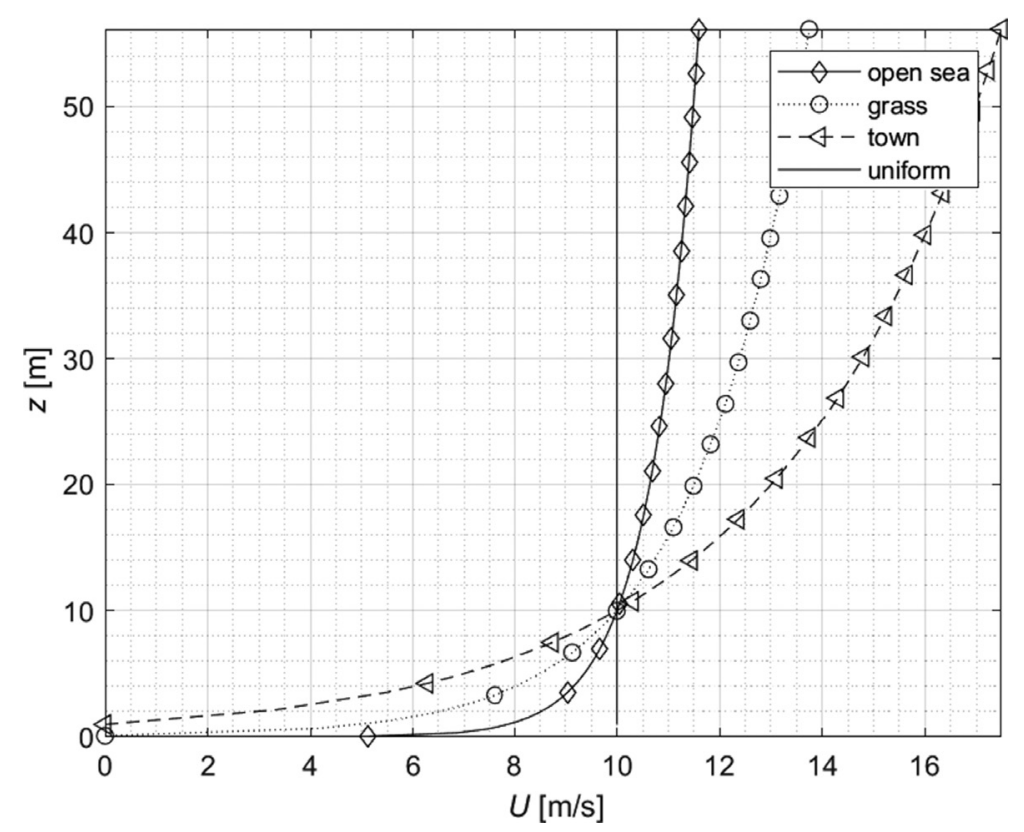

Figure 3: Wind profiles for the given $10 \mathrm{~m} / \mathrm{s}$ wind speed at $10 \mathrm{~m}$ above surface: open sea, grass, town and uniform profile.

is linked with the way the wind coefficients were determined and defined, which is discussed in the next section.

\subsection{Wind coefficients}

The relationship between wind speed and corresponding wind force is formed by the nondimensional wind coefficient in eqn (2). This wind coefficient is generally determined in wind tunnel tests, where a wind-induced force is measured and used to derive the wind coefficient, as is shown in eqn (6) for $C_{\mathrm{X}}$

$$
C_{X}(\varphi)=\frac{X_{\mathrm{w}}}{\frac{1}{2} \cdot \rho_{\mathrm{a}} U_{\mathrm{ref}}^{2} \cdot A_{1}}
$$

Wind coefficients for ships can be retrieved from various sources and used by means of eqn (2) to obtain wind forces. In order to use the coefficients properly, however, additional 
information is needed concerning how the coefficients were derived from experiments or simulations. Considering eqn (6), for example, it is important to know which reference area was used to derive the wind coefficient. As an example for container ships, it is common to use both the fully stacked (e.g. [10]) and the ballast area (e.g. [11]) in the definition of $A_{\text {L }}$. When using eqn (2a), the choice of the reference area to be used should match the reference area used to derive the coefficient; if not, large errors can be made.

The choice of reference speed is even more important, because of the squared dependency in the force calculation. The reference speed to be considered when using a wind coefficient should be linked to the wind profile used in the tunnel to derive the coefficient and the choice of $U_{\text {ref }}$ in eqn (6). This is often not taken into account during the analysis or even unknown to the user of the coefficients. The wind profile encountered in the wind tunnel at the position of the ship is a function of the roughness in the tunnel and the length of the section between the inlet and the model [8]. The profile in the tunnel can vary between nearly uniform (thin boundary layer) and boundary layers similar to profiles encountered in nature [5].

In some publications, a regression study is performed based on wind tunnel coefficients [12]. Here, it is important to know which wind profile was present in the various wind tunnel experiments. Blendermann [2] proposed a method to convert non-uniform wind profiles to equivalent uniform profiles and vice versa. This method can also be used to determine the reference pressure values for wind force calculations, which is discussed in the next section.

Next to the wind profile discussion, there are other factors of importance when using wind coefficients, especially for large container ships:

- Wind coefficients depend on the shape of the ship. For some ship types (e.g. oil tankers), the shape has remained invariant over the last decades. For container ships, the length to beam ratio as well as the position of accommodation and funnel has changed, leading to differences in wind coefficients. MariKom [11] shows wind coefficients for ULCS.

- For container ships, there are usually two loading configurations taken into account, ballast and fully loaded. In reality, the stacking is more random (see Fig. 1), meaning that the wind pressure distribution changes, in function of the exact container stacking. In [13], this is modelled based on aerodynamic theory and wind tunnel tests, showing large differences in $X$ and $N$ for slightly of bow/stern wind, with random stacking.

An in-depth discussion of these parameters is out of scope of this paper.

\section{WIND PRESSURE CALCULATION}

In this section, the calculation of $q_{\text {ref }}$, to be used in eqn (2) is discussed for the wind profiles shown in Fig. 3, assuming that the wind coefficients have been derived for a uniform wind profile. First, wind speeds and pressures are calculated for the different profiles, both at the mean height $\bar{H}$ and averaged over the mean height, based on the dimensions of the UASC Barzan. Based on these calculations, Blendermann's method [2] is used to calculate a reference pressure for the profiles with varying roughness.

\subsection{Calculation of wind speed and dynamic pressure}

For the wind profiles defined earlier (Fig. 3 and Table 2), the wind speeds and dynamic pressure values at different heights are calculated. As stated earlier, all profiles are defined by a $U_{10}$ of $10 \mathrm{~m} / \mathrm{s}$. The wind pressure at each vertical position $(z)$ is calculated using eqn (7a), 
while the average pressure between $z_{0}$ and $h$ is given in eqn (7b), assuming that the surface area is invariant over a height of the ship.

$$
\begin{array}{r}
q(z)=\frac{1}{2} \cdot \rho_{a} \cdot U(z)^{2} \\
\overline{q_{h}}=\frac{\int_{z_{0}}^{h} \frac{1}{2} \cdot \rho_{a} \cdot U(z)^{2} d z}{h}
\end{array}
$$

Equation (7b) can be solved analytically for the logarithmic profile, leading to eqn (8).

$$
\overline{q_{h}}=\frac{u_{*}^{2} \cdot \rho_{a}}{2 \cdot \kappa^{2} \cdot h} \cdot\left[\ln ^{2} \frac{h}{z_{0}} \cdot h-2 \cdot h \cdot \ln \frac{h}{z_{0}}+2 \cdot h-2 \cdot z_{0}\right]
$$

The average pressure over the mean height can be obtained by replacing $h$ in eqns (7b) and (8) with the mean height. For all four profiles, the wind speed $(U)$ and the dynamic pressure $(q)$ at the mean ship height $(\bar{H})$ are given in Table 3 .

\subsection{Determination of reference wind speed}

The results in Table 3 indicate that the choice of reference speed is not a trivial question. It clearly shows that the wind speed at the top of a ship, for a rough profile, is much higher than the one measured at $10 \mathrm{~m}$ height. This difference becomes even more pronounced when comparing the pressures, due to the squared dependency on the wind speed.

Now the question remains which pressure to take as reference pressure in wind force calculations. An inaccurate assessment of this quantity can lead to large errors, which are an order of magnitude higher than differences between various values for wind coefficients for similar ships. As previously indicated, Blendermann's method is suited to define $q_{\text {ref }}$ for non-uniform wind profiles, using wind coefficients derived for uniform profiles [2].

Blendermann proposes to use the pressure at the mean height for surge $(X)$. For sway $(Y)$ and yaw $(N)$, a weighted average between the average wind pressure over the mean height and the wind pressure at the mean height $\left(q_{\mathrm{ref}}\right)$ is proposed. For the roll moment $(K)$, the relationship is less obvious and both options to calculate $q_{\text {ref }}$ are listed. Formulae for computing $q_{\text {ref }}$ are summarized in Table 4 . The value of $k_{\mathrm{q}}$ is the weighting factor derived by Blendermann. It is a function of the wind direction, with a default value of 0.6.

Table 3: Wind speeds and wind pressures for four wind profiles, at the mean height $\left(q_{\bar{H}}\right)$ and averaged over the mean height $\left(\overline{q_{\bar{H}}}\right)$.

\begin{tabular}{lrrr}
\hline & $U_{\bar{H}}$ & $q_{\bar{H}}$ & $\overline{q_{\bar{H}}}$ \\
\cline { 2 - 4 } & {$[\mathrm{m} / \mathrm{s}]$} & {$\left[\mathrm{N} / \mathrm{m}^{2}\right]$} & {$\left[\mathrm{N} / \mathrm{m}^{2}\right]$} \\
\hline Uniform & 10.000 & 61.250 & 61.250 \\
Water & 11.370 & 79.180 & 67.350 \\
Long grass & 13.217 & 107.001 & 77.606 \\
Town & 16.434 & 165.432 & 100.579 \\
\hline
\end{tabular}


Table 4: Definition reference dynamic pressures for different force components.

\begin{tabular}{ll}
\hline Force & $q_{\text {ref1 }}\left[\mathrm{N} / \mathrm{m}^{2}\right]$ \\
\hline$X$ & $q_{\bar{H}}$ \\
$Y$ & $k_{\mathrm{q}} \cdot \overline{q_{\bar{H}}}+\left(1-k_{\mathrm{q}}\right) \cdot q_{\bar{H}}$ \\
$N$ & $k_{\mathrm{q}} \cdot \overline{q_{\bar{H}}}+\left(1-k_{\mathrm{q}}\right) \cdot q_{\bar{H}}$ \\
$K$ & $q_{\bar{H}}$ or same as for $Y$ \\
\hline
\end{tabular}

Table 5: Reference pressures for four wind profiles.

\begin{tabular}{lccccc}
\hline & \multicolumn{2}{c}{$Y, N, K$} & & \multicolumn{2}{c}{$X, K$} \\
\cline { 2 - 3 } \cline { 5 - 6 } & $q_{\text {ref }}\left[\mathrm{N} / \mathrm{m}^{2}\right]$ & $q_{\mathrm{ref}} / q_{0}[-]$ & & $q_{\mathrm{ref}}\left[\mathrm{N} / \mathrm{m}^{2}\right]$ & $q_{\mathrm{ref}} / q_{0}[-]$ \\
\hline Uniform & 61.250 & 1.000 & & 61.250 & 1.000 \\
Sea & 74.748 & 1.220 & & 79.180 & 1.293 \\
Long grass & 95.243 & 1.555 & & 107.001 & 1.747 \\
Town & 139.491 & 2.277 & & 165.432 & 2.701 \\
\hline
\end{tabular}

The definition of $\bar{H}$ may not be appropriate for all wind directions, as it is defined based on the lateral wind surface and the length of the ship (eqn (1)). For $X$ force for example, a definition based on the frontal surface might be more suitable. Also, this definition might need to be adjusted with ship type, as the superstructure shape depends on the type of ship. These observations are at this stage however premature and need to be backed by a sensitivity analysis, which will be part of future research. In Table 5, the reference pressures are listed. $q_{0}$ corresponds to the pressure for a uniform velocity profile. It is used for comparison with the other profiles. For the different profiles, the ratio between $q_{0}$ and $q_{\text {ref }}$ is shown. For wind coming from sea, the difference is in the order of $20 \%$ to $30 \%$. For rough surfaces, the reference pressure proposed by Blendermann is more than double the pressure at $10 \mathrm{~m}$ height. This clearly indicates that, if the wind coefficients have been derived based on a uniform wind profile, the reference pressure should not be chosen by default as the pressure at $10 \mathrm{~m}$ height. In the next section, Blendermann's method is compared with CFD computations in a uniform and non-uniform wind profile for a simplified ship geometry based on the Barzan general arrangement plan.

\section{CFD ANALYSIS}

In this section, results of CFD simulations with a uniform and rough, non-uniform, wind field are presented using a simplified geometry of the UASC Barzan (Fig. 4). The characteristic parameters of this shape are given in Table 6 . The simulations were performed using FINE/Marine, using a uniform inlet velocity and a non-uniform velocity profile. The forces and moments on the hull were computed for relative wind angles of 0, 90 and 180 degrees. 


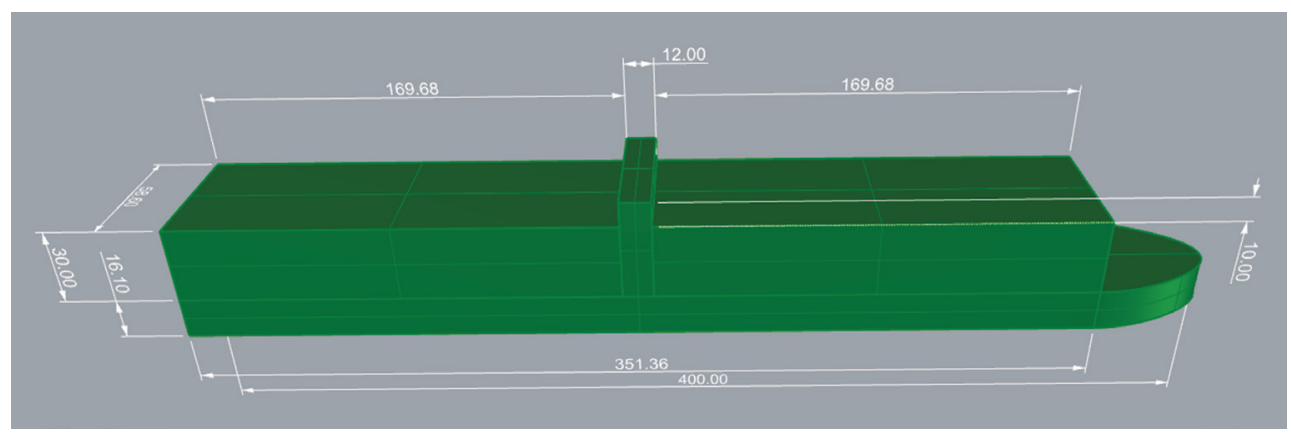

Figure 4: Geometry of the simplified model of the UASC Barzan.

Table 6: Characteristics simplified hull shape UASC Barzan, used for CFD analysis.

\begin{tabular}{lccc}
\hline Variable [unit] & Value & Variable & Value \\
\hline$L_{\mathrm{OA}}[\mathrm{m}]$ & 400.0 & $D[\mathrm{~m}]$ & 30.6 \\
$L_{\mathrm{pp}}[\mathrm{m}]$ & 400.0 & $T[\mathrm{~m}]^{*}$ & 14.5 \\
$B[\mathrm{~m}]$ & 58.6 & $A_{\mathrm{f}}\left[\mathrm{m}^{2}\right]$ & 3,287 \\
$H[\mathrm{~m}]$ & 56.1 & $A_{1}\left[\mathrm{~m}^{2}\right]$ & 17,100 \\
$\bar{H}[\mathrm{~m}]$ & 42.75 & & \\
\hline
\end{tabular}

*In the CFD analysis, only the wind surface is modelled. The draft and depth values are used to compute the bow section height with no container stacks, which equals $16.1 \mathrm{~m}$ (Fig. 4).

A set of $2 \mathrm{D}$ computations were used to verify that the velocity profile (and the profiles for the turbulent kinetic energy and turbulent dissipation) remained constant over the length of the domain. These profiles are shown in Fig. 5. For the CFD computations, the reference velocity at $10 \mathrm{~m}\left(U_{10}\right)$ is higher $(11.81 \mathrm{~m} / \mathrm{s})$ than in the previous sections, but again the same for both uniform and non-uniform profile.

\subsection{Computational domain and boundary conditions}

The computational domain is a rectangular box with sides $3,000 \mathrm{~m}, 2,000 \mathrm{~m}$ and $500 \mathrm{~m}$. For the inlet and sides of the domain, a far-field boundary condition is used. This allows to set profiles for the velocity, turbulent kinetic energy and turbulent dissipation. At the top boundary, the far-field boundary condition is used, with the uppermost values of the profiles used at the inlet. This ensures that no gradients can develop at the top boundary. For the computations with uniform flow, constant values are prescribed at the inlet and top that correspond to the profile values at the reference height of $10 \mathrm{~m}$. A prescribed pressure boundary condition is used at the outlet. At the bottom boundary, a solid boundary condition with wall functions and roughness is used for the simulations with the non-uniform inlet profile, while for the simulations in uniform flow, a slip boundary condition is utilized. 

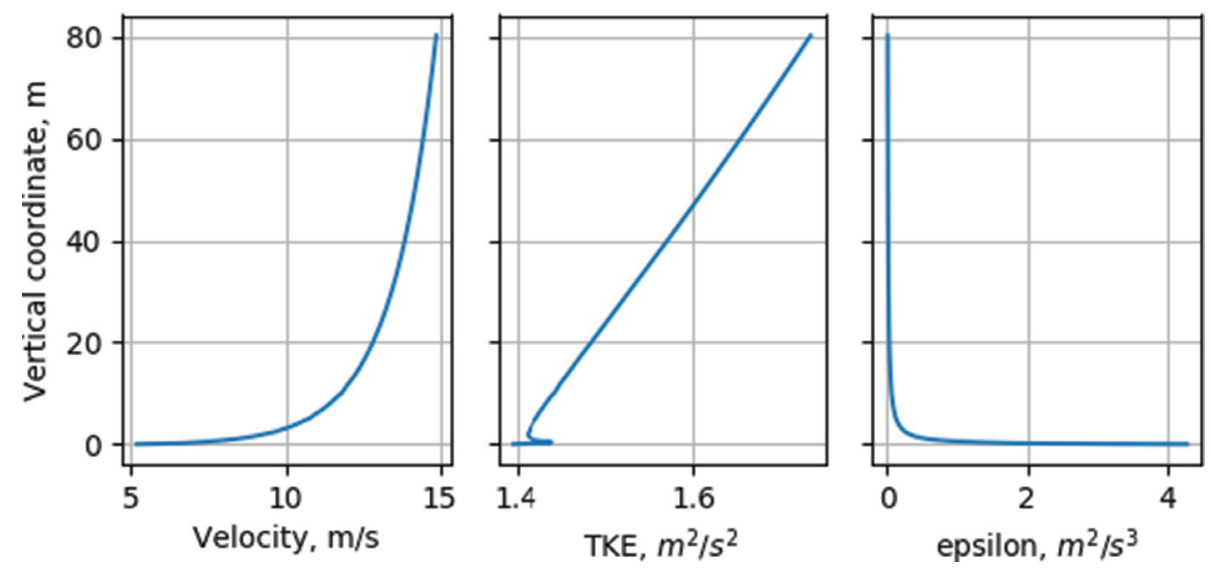

Figure 5: Bottom $80 \mathrm{~m}$ of the non-uniform velocity profile, turbulent kinetic energy and turbulent dissipation applied at the inlet of the computational domain.

\subsection{Computational grid}

For each of the six computations, a separate grid is constructed. For the cases with uniform flow, the grids contain approximately 1 million cells, while for the cases with non-uniform flow, the grid sizes vary between 3.2 (for the 0 and 180 degree cases) and 3.6 million cells (for the 90 degree case). The larger cell count for the computations with velocity profile as compared to the computations with uniform velocity is caused by the requirement to have more cells in areas where large gradients occur, in this case near the bottom of the domain.

\subsection{Solver settings}

The solver was run in steady mode (first-order time integration), with a single fluid with the properties of air at $0 \mathrm{~m}$ International Standard Atmosphere (ISA): density equals 1.225 $\mathrm{kg} / \mathrm{m}^{3}$ and dynamic viscosity equals $1.7894 \times 10^{-5} \mathrm{~Pa}$ s. The $k \omega-$ Shear Stress Transport (SST) turbulence model is used as a closure for the Reynolds-averaged Navier Stokes equations. The solution is initialized using a uniform velocity field equal in value to the reference velocity at $10 \mathrm{~m}$.

\subsection{Results and discussion}

As mentioned before, computations using a uniform and a non-uniform profile were performed. The relationship between the uniform and non-uniform profile is presented in the same way as has been done in the previous discussion, by calculating the wind speed and pressure at the mean height as well as the average pressure (Table 7). It can be seen that the 'level of non-uniformity' falls between the open sea and grass profiles shown in Fig. 3. Table 8 gives the reference pressures calculated using Blendermann's method (see Table 4 for definitions of reference pressures).

The forces acting on the ship for the different wind directions and force components are summarized in Table 9. The first column shows the force component considered and the incoming wind direction. The second and third columns give the forces calculated using 
Table 7: Comparison of uniform and non-uniform profile used in CFD simulations.

\begin{tabular}{lccc}
\hline & $U_{\bar{H}}$ & $q_{\bar{H}}$ & $\overline{q_{\bar{H}}}$ \\
\cline { 2 - 4 } & {$[\mathrm{m} / \mathrm{s}]$} & {$\left[\mathrm{N} / \mathrm{m}^{2}\right]$} & {$\left[\mathrm{N} / \mathrm{m}^{2}\right]$} \\
\hline Uniform & 11.810 & 85.429 & 85.429 \\
Non-uniform & 13.973 & 119.590 & 97.381 \\
\hline
\end{tabular}

Table 8: Reference pressures for uniform and non-uniform profile used in CFD simulations.

\begin{tabular}{lccccc}
\hline & \multicolumn{2}{c}{$Y, N, K$} & & \multicolumn{2}{c}{$X, K$} \\
\cline { 2 - 3 } \cline { 5 - 6 } & $q_{\mathrm{ref}}\left[\mathrm{N} / \mathrm{m}^{2}\right]$ & $q_{\mathrm{ref}} / q_{0}[-]$ & & $q_{\mathrm{ref}}\left[\mathrm{N} / \mathrm{m}^{2}\right]$ & $q_{\mathrm{ref}} / q_{0}[-]$ \\
\hline Uniform & 85.429 & 1.000 & & 85.429 & 1.000 \\
Non-uniform & 105.078 & 1.230 & & 119.590 & 1.396 \\
\hline
\end{tabular}

Table 9: Force components for calculated wind directions, for uniform profile, non-uniform profile and Blendermann method.

\begin{tabular}{lccccc}
\hline & $\begin{array}{l}F[\mathrm{kN}(\mathrm{m})] \\
\text { uniform CFD }\end{array}$ & $\begin{array}{l}F[\mathrm{kN}(\mathrm{m})] \\
\text { non-uniform } \\
\text { CFD }\end{array}$ & $\begin{array}{l}F[\mathrm{kN}(\mathrm{m})] \\
\text { non-uniform } \\
\text { Blendermann }\end{array}$ & Ratio CFD & $\begin{array}{l}\text { Ratio } \\
\text { Blendermann }\end{array}$ \\
\hline$X, 0$ degree & -214 & -299 & -299 & 1.398 & 1.396 \\
$X, 180$ degree & 263 & 367 & 367 & 1.397 & 1.396 \\
$Y, 90$ degree & 1,805 & 1,919 & 2,220 & 1.063 & 1.230 \\
$K, 90$ degree & 41,477 & 51,602 & 51,017 & 1.244 & 1.230 \\
\hline
\end{tabular}

CFD. The next column shows the force calculated based on the force taken from CFD simulations with the uniform profile, multiplied by the ratio between $q_{\text {ref }}$ and $q_{0}$ (Table 8). This ratio and the ratio of the CFD calculated forces are given in the last two columns.

It can be clearly seen that for the $X$ force, Blendermann's method gives an accurate result. For the roll moment $(K)$, it seems like the weighted average between $\overline{q_{\bar{H}}}$ and $q_{H}$ gives the best result. For the lateral force, Blendermann seems to overestimate the force, in comparison with the CFD simulations.

\section{CONCLUSION}

The paper discusses the application of wind coefficients to calculate wind forces acting on large container ships, focussing on the choice of reference pressure. The wind speed at $10 \mathrm{~m}$ height is widely considered as the reference speed, and it is often used to determine the reference pressure. The reference pressure is used to calculate wind forces in combination with wind coefficients, usually derived from wind tunnel tests. However, the wind profile in the wind tunnel can differ significantly from the profile encountered in reality, which calls for a careful selection of the reference pressure. 
In general, wind tunnel profiles are close to uniform. In some cases, they will resemble an open sea profile, which only slightly deviates from a uniform profile. In these cases, taking the reference pressure at $10 \mathrm{~m}$ will only lead to minor inaccuracies.

Over rough terrains, the wind speed varies significantly along the height of the ship, which becomes more important with the constant increase in the air draughts of container ships. When the wind speed equals $10 \mathrm{~m} / \mathrm{s}$ at $10 \mathrm{~m}$ height, the wind speed at the top of the bridge can easily reach $16 \mathrm{~m} / \mathrm{s}$. In this case, there is a large deviation from the uniform profile. The choice of reference pressure to be used in the calculation of wind forces is thus not straightforward.

Blendermann suggests a method to calculate the reference pressure based on the pressure at mean height and average pressure over this height. By applying this method to an ULCS, the reference pressures using Blendermann's approach are a factor 2 to 3 higher than the pressure at $10 \mathrm{~m}$, meaning that the wind forces could be underestimated by the same factor. CFD calculations show that a reference pressure determined using Blendermann's method can indeed be used for scaling $X$ and $K$, but overestimate the scaling factor for $Y$. More CFD calculations are needed to further investigate this matter and draw sound conclusions.

The paper clearly shows that when the real wind profile is non-uniform while the set of wind coefficients is based on tests performed with a uniform profile, the simplified use of the wind pressure at $10 \mathrm{~m}$ height as the reference one will lead to a large underestimation of the total wind force.

$\begin{array}{lll}A_{1} & {\left[\mathrm{~m}^{2}\right]} & \text { lateral wind surface } \\ A_{\mathrm{f}} & {\left[\mathrm{m}^{2}\right]} & \text { frontal wind surface } \\ B & {[\mathrm{~m}]} & \text { beam } \\ C_{\mathrm{X}, \mathrm{YN}, \mathrm{K}} & {[-]} & \text { wind coefficient } \\ D & {[\mathrm{~m}]} & \text { depth } \\ g & {\left[\mathrm{~m} / \mathrm{s}^{2}\right]} & \text { gravitational acceleration } \\ \bar{H} & {[\mathrm{~m}]} & \text { mean ship height } \\ H & {[\mathrm{~m}]} & \text { air draught } \\ K & {[\mathrm{Nm}]} & \text { roll wind moment } \\ L_{\mathrm{OA}} & {[\mathrm{m}]} & \text { length overall } \\ L_{\mathrm{PP}} & {[\mathrm{m}]} & \text { length between perpendiculars } \\ N & {[\mathrm{Nm}]} & \text { yaw wind moment } \\ q_{\mathrm{ref}} & {\left[\mathrm{N} / \mathrm{m}^{2}\right]} & \text { reference wind pressure } \\ q_{\bar{H}} & {[\mathrm{~Pa}]} & \text { mean dynamic pressure over mean ship height } \\ q_{\bar{H}} & {[\mathrm{~Pa}]} & \text { dynamic pressure at mean height } \\ T & {[\mathrm{~m}]} & \text { draft } \\ u_{*} & {[\mathrm{~m} / \mathrm{s}]} & \text { friction velocity } \\ U_{10} & {[\mathrm{~m} / \mathrm{s}]} & \text { wind speed at } 10 \text { m height } \\ U_{\bar{H}} & {[\mathrm{~m} / \mathrm{s}]} & \text { wind speed at mean height } \\ U_{\text {ref }} & {[\mathrm{m} / \mathrm{s}]} & \text { reference wind speed } \\ X & {[\mathrm{~N}]} & \text { longitudinal wind force } \\ Y & {[\mathrm{~N}]} & \text { lateral wind force } \\ z_{0} & {[\mathrm{~m}]} & \text { roughness length } \\ \mathrm{Z} & {[\mathrm{m}]} & \text { height above surface } \\ \kappa & {[-]} & \text { Von Karman coefficient } \\ \varphi & {\left[{ }^{\circ}\right]} & \text { incoming wind angle } \\ \rho_{\mathrm{a}} & {\left[\mathrm{kg} / \mathrm{m}^{3}\right]} & \text { air density } \\ & & \\ & & \end{array}$




\section{REFERENCES}

[1] SEA Europe, 2017 Market Forecast Report. 2017.

[2] Blendermann, W., Estimation of wind loads on ships in wind with a strong gradient. 14th International Conference on offshore mechanics and arctic engineering (OMAE), pp. 271-7, 1995.

[3] ITTC, ITTC Symbols and Terminology List Version 2017. 2017.

[4] RINA, Significant ships of 2015. 2016.

[5] Andersen, IMV., Wind loads on post-panamax container ship. Ocean Engineering, 58, pp. 115-34, 2013.

[6] Coelingh, JP., Wijk, AJM. \& Holtslag, AAM., Analysis of wind speed observations over the North Sea. Journal of Wind Engineering and Industrial Aerodynamics, 61, pp. 51-69,1996.

[7] Garatt, JR., Review of drag coefficients over oceans and continents. Monthly Weather Review. 1977.

[8] Simiu, E. \& Scanlan, RH., Wind effects on structures : Fundamentals and applications to design. 1996.

[9] Charnock, Wind stress on a water surface. Journal of the Royal Meteorological Society, 81, pp. 639-40, 1955.

[10] Janssen, WD, Blocken, B \& van Wijhe, HJ., CFD simulations of wind loads on a container ship : Validation and impact of geometrical simplifications. Journal of Wind Engineering and Industrial Aerodynamics, 166, pp. 106-16, 2017.

[11] MariKom, HPA., Determination of aerodynamic drag ceofficients of ship models with different air draughts and loading conditions. 2015.

[12] Fujiwara, T. \& Nimura, T., New Estimation Method of Wind Forces Acting on Ships on the Basis of Mathematical Model. The International Society of Offshore and Polar Engineers (ISOPE), editor. Proceedings of the 15th International Offsohre and Polar Engineering Conference. 2005, Seoul, Korea.

[13] Fujiwara, T., Tsukada, Y. \& Kitamura, F., Experimental Investigation and Estimation on Wind Forces for a Container Ship. Nineteenth (2009) International Offshore and Polar Engineering Conference, 1, pp. 555-62, 2009. 